\title{
A MEMÓRIA COMO PROMOTORA DE INTERCULTURALIDADE EM MAPUTO, ATRAVÉS DA PRESERVAÇÃO DA ESTATUÁRIA COLONIAL
}

\author{
Vítor de Sousa
}

\begin{abstract}
Resumo
Por não se tratar de um assunto encerrado, onde a força das ideologias e dos reusos poderá alterar profundamente, ou até inverter, os modos da sua evocação, o passado colonial pode revelar-se problemático (Vecchi, 2018a). É o caso do colonialismo português que, de forma recorrente é invocado para sublinhar ressentimentos: quer do país que foi colonizado, quer do país colonizador (Ferro, 2009). Moçambique, logo que eclodiu em Portugal a Revolução do 25 de Abril de 1974, promoveu o apagamento dos símbolos do colonialismo. A previsível atitude, tendente a mostrar que a colonização tinha acabado veio, depois, a ser corrigida pelos futuros Governos, com as estátuas coloniais (pelo menos as que restaram), a serem deslocalizadas, onde passaram a poder ser observadas e contextualizadas. Tratou-se de uma ação com vista à preservação da memória, que pode permitir o desenvolvimento de dinâmicas interculturais, esbatendo o referido ressentimento: promovendo a problematização para perceber determinadas lógicas e, ao mesmo tempo, preencher vazios na memória esquecida e na identidade dos moçambicanos (Khan, Falconi \& Krakowska, 2016). Este artigo referencia os casos relativos à nova vida de duas estátuas coloniais em Maputo - a de Mouzinho de Albuquerque e a de Salazar -, em tempo pós-colonial, e à permanência, até hoje, daquele que foi o primeiro vestígio monumental do Estado Novo (o Monumento aos Mortos da Primeira Guerra Mundial), observando a importância que tem a preservação da memória na vida de um país, ou de uma nação, mesmo estando associada ao antigo colonizador. Esta espécie de descolonização mental (Mbembe, 2017; Thiong'o, 1986), passa pela problematização da forma como o passado colonial pesa nas relações interculturais nos dias de hoje em Moçambique, quando o país se relaciona com o antigo colonizador, permitindo que os seus habitantes olhem para o passado como forma de construir dinâmicas de futuro.
\end{abstract}

\section{MeMORY AS AN INTERCULTURALITY BoOSTER IN MAPUTO, THROUGH THE PRESERVATION OF THE COLONIAL STATUARY}

\begin{abstract}
Since this is a matter that is not yet resolved, where the strength of ideologies and reuses may change deeply or even reverse the ways it is evoked, the colonial past may become a problem (Vecchi, 2018a). This is the case of Portuguese colonialism which is frequently invoked to stress resentments: whether from the country that was colonised or the colonising country (Ferro, 2009). As soon as the Portuguese Revolution of 25 April 1974 took place, Mozambique promoted the elimination of colonialism symbols. This predictable attitude, aiming to show that the colonisation had ended, was later amended by the future Governments, with the colonial statues (at least, the ones that remained) being relocated to a place where they may be observed and contextualised. This action aimed to preserve the memory, which may enable the development of intercultural dynamics, softening the mentioned resentment: promoting questioning, in order to
\end{abstract}


understand certain logics and, at the same time, filling gaps in the forgotten memory and in the Mozambican identity (Khan, Falconi \& Krakowska, 2016). This paper refers to the cases related to the new life of two colonial statues in Maputo - Mouzinho de Albuquerque and Salazar -, during the post-colonial period and the permanence, until today, of the first monumental trace of Estado Novo [Second Republic] (Monumento aos Mortos da Primeira Guerra Mundial [World War I monument]), showing the importance that the preservation of memory has in a country or a nation's life, even when it is associated with the former coloniser. This sort of mental decolonisation (Mbembe, 2017; Thiong'o, 1986), aims the questioning of the way the colonial past weighs on the current intercultural relations, in Mozambique, when the country establishes a relation with the former coloniser, allowing its inhabitants to look at the past as a way to build future dynamics.

KEYWORDS

Memory, history, coloniality, post-coloniality, interculturality

\section{INTRODUÇÃo}

As estátuas pontuam o espaço público, como é o caso das cidades, onde existem maiores aglomerados populacionais. Como monumentos públicos que são, expressam a memória coletiva e as suas representações e são normalmente relacionadas com temáticas ou figurações ligadas à identidade nacional, pela mão de quem, nessas circunstâncias, detém o poder.

Uma estátua é um objeto imóvel (uma escultura em três dimensões), que pode representar uma entidade real ou imaginária. Os governos coloniais erigiram estátuas nos territórios que colonizaram relacionadas com a metrópole ou com o seu imaginário. Margarida Calafate Ribeiro (2004) refere-se ao "império como imaginação do centro", sustentando que a elaboração de uma imagem de Portugal enquanto centro foi concretizada exatamente através do império. Foram as marcas do império, que representava a "nação em excesso, que foi deslocada para longe" (Richards, 1993), especialmente nessa relação com as "comunidades imaginadas" (Anderson, 1993), que tentaram fixar a ligação. Mesmo que se tratasse de um "Império de Papel", como conta Leonor Pires Martins (2012), em que as regiões africanas foram tomando forma na cabeça dos portugueses através das imagens, mas que evidenciava a existência de alguma fragilidade por parte de Lisboa.

Moçambique, nomeadamente a sua capital, Maputo (outrora Lourenço Marques), não fugiu à regra. Numa primeira fase, mesmo antes da independência do país, em junho de 1975, as estátuas coloniais foram derrubadas (à exceção do Monumento aos Mortos da Primeira Guerra Mundial, feito em pedra) e, muitas delas, danificadas. Numa segunda fase, o Governo moçambicano pretendeu mostrar a anterior estatuária, preservando a memória e contextualizando-a. É o caso da estátua equestre que homenageava Mouzinho de Albuquerque, que estava colocada bem no centro de Maputo (derrubada em maio de 1975), na Praça que no tempo colonial tinha o nome do militar português, que foi Comissário Régio de Moçambique entre 1896 e 1898, que foi trasladada para o Fortaleza de Maputo, onde pode ser vista por todos os habitantes, e que os 
recém-casados utilizam como fundo para as fotografias da sua festa de casamento. Para além disso, uma outra estátua representando Salazar, que no tempo colonial estava edificada também no centro da capital do país (derrubada em maio de 1974), foi colocada na Biblioteca Nacional de Moçambique, voltada para a parede, como que estando de castigo. Em ambos os casos, trata-se de uma espécie de descolonização mental (Mbembe, 2017; Thiong'o, 1986), que passa por problematizar a forma de como o passado colonial pesa nos dias de hoje em Moçambique. Nesse sentido, muito embora o conceito de interculturalidade possa ser pouco consensual - havendo quem o associe ao tempo das descobertas portuguesas, numa inspiração claramente luso tropical -, a verdade é que, durante o período colonial português, vigorava uma espécie de interculturalidade invertida (Stoer \& Cortesão, 1999), tutelada pelo colonizador, com o acento tónico na ideia de "portugalidade".

O tempo pós-colonial não cancela o tempo colonial, embora o recicle. Nesse sentido, e como metáfora desse tempo passado-presente, a estátua colonial representa uma ausência/indiferença, mas ao mesmo tempo, devidamente contextualizada, pode assumir-se enquanto pilar do edifício da memória de Moçambique e, por arrastamento, também, de Portugal.

\section{A MEMÓRIA COLETIVA E A HISTÓRIA}

A herança, enquanto património, tornou-se em vários países numa palavra de ordem, evocando uma multiplicidade de associações emocionais. Para o Estado, constitui um meio oportunista para satisfazer as necessidades sociais do eleitorado, ao mesmo tempo que promove os objetivos políticos de construção da nação. No entendimento de Sabine Marschall (2009) - que escreveu sobre a ideia de herança no período pós-apartheid na África do Sul -, a herança assenta num conceito maleável e ambíguo, cheio de paradoxos, e pode ser utilizado de várias maneiras, apoiando, por vezes, políticas, económicas, sociais e culturais contraditórias. Desde o início dos anos 90 do século XX que o discurso da herança patrimonial emergiu - não só na África do Sul, mas em vários outros países -, como um dos principais locais para negociar questões de cultura, de identidade e de cidadania, sugerindo o que é autêntico, o que são as raízes profundas da identidade cultural e a "essência" de um sentido de nacionalidade (Shepherd \& Robins, 2008). O património é difícil de definir, por ser abrangente, contendo artefactos e estruturas tangíveis que remetem para o passado, bem como paisagens e aspetos intangíveis da cultura, como tradições, costumes e memórias orais. O património relaciona-se tanto com o passado como com o presente (Marschall, 2009).

A comemoração manifesta-se, entre outras formas, na renomeação de ruas, cidades e prédios públicos; na construção de novos museus, de centros de documentação e de interpretação; na reencenação de batalhas e eventos históricos; na identificação e na marcação oficial de novos locais de património; bem como na instalação de memoriais, monumentos e estátuas públicas. Como monumentos públicos que são, as estátuas expressam a memória coletiva e a representação e são normalmente relacionados com 
as temáticas ou as figurações ligadas à identidade nacional, pela mão de quem, nessas circunstâncias, detém o poder.

Maputo não fugiu a esta tendência, muito embora a destruição dos vestígios coloniais, que se fez sentir na sequência da Revolução do 25 de Abril, em Portugal, antes mesmo da independência de Moçambique, tenha dado lugar à sua preservação, na tentativa de mostrar aos moçambicanos vestígios da memória de quando estavam sob domínio português.

A memória coletiva - conceito criado por Maurice Halbwachs, em 1925, depois de concluir que a memória é partilhada, transmitida e construída pelo grupo ou pela sociedade -, deve ser entendida sempre na sua pluridimensionalidade, já que a memória individual de um sujeito ou a que é referente a um país estão na base da formulação de uma identidade. Noutro patamar estará a história, que promove a síntese dos acontecimentos destacáveis de uma nação, o que faz das memórias coletivas apenas um somatório de detalhes. Sobre a relação entre história e memória, o autor refere que "a história começa somente do ponto onde acaba a tradição, momento em que se apaga ou se decompõe a memória social. Enquanto uma lembrança subsiste, é inútil fixá-la por escrito" (Halbwachs, 1950/1990, p. 80).

Trata-se de uma ideia partilhada por Pierre Nora, embora este historiador observe que a memória se tornou num objeto da história, pelo que equivale à própria história. Destaca que o processo de aceleração verificado na história, decorrente da massificação mediatizada da sociedade, provocou o fim da tradição da memória, como consequência da radical mudança de prática relativa aos arquivos, que deixaram de ter uma visão crítica, para apenas servirem para uso instrumental, contrariando a "memória viva". Nesse sentido, refere a cristalização das formas de memória, considerando-as mesmo "memórias-prótese", que se substituem à experiência vivenciada (Nora, 1989). Defende a ideia de que já não existe memória, uma vez que ela é apenas revivida e ritualizada, pelo que a sociedade se serve hoje da história para lhe conferir lembranças. Nesse sentido, na sociedade contemporânea não existe a possibilidade para uma história-memória, como acontecia no século XIX. Refere que a separação entre memória e história produz significados bem definidos, com a memória a ser encarada como tradição, assente na herança, viva e dinâmica e a história a representar o seu oposto, separando e selecionando os factos. O historiador refere, assim, que as sociedades modernas eliminaram por completo a memória, sendo que a que existe se assume enquanto história. E, face à eventualidade de não se ter memória, refere a possibilidade de aceder a uma memória reconstituída que dê sentido à identidade, como a criação de arquivos, a organização de celebrações, entre outras, em que os lugares de memória se assumem como um espaço onde o ritual de uma memória-história pode traduzir-se como lembrança (Nora, 1989).

As narrativas culturais, históricas e educativas objetivam memórias e pós-memórias, sendo demonstrável a sua produtividade através, por exemplo, de uma análise da memorialização da Guerra Colonial no contexto contemporâneo português (Ribeiro \& Ribeiro, 2018) e que, neste contexto, também se revela importante para Moçambique. 
Segundo António Sousa Ribeiro (2018), uma das mais produtivas reflexões sobre estas temáticas traduz-se no conceito de "pós-memória", proposto por Marianne Hirsch na década de 90 do século XX, cuja importância "reside na forma como possibilita pensar a posição complexa das gerações subsequentes no âmbito dos processos de memória" (Ribeiro, 2018, p. 15). De forma paradoxal, "pós-memória", será uma memória que não foi vivida, mas que, "pela sua violência e pelo significado marcante das suas consequências, nomeadamente no âmbito da socialização familiar, se impõe a uma geração seguinte com suficiente força para ficar indelevelmente inscrita" (Ribeiro, 2018, p. 15). É nesse sentido, que a pós-memória "se transforma numa das pedras de toque que permitem dar um conteúdo performativo concreto à relação com um passado violento" (Ribeiro, 2018, p. 15). O que permite, também, codificar essas memórias em histórias e em narrativas, preservando-as e possibilitando que novos membros compartilhem uma história em grupo.

Sheila Khan sublinha a existência de um pós-colonialismo moçambicano, diferenciado da dinâmica pós-colonial de expressão em língua portuguesa, facto que diz sobressair na escrita de João Paulo Borges Coelho. A investigadora faz a aproximação de três obras do autor - As visitas do Dr. Valdez (2004), Crónica da Rua 513.2 (2006) e Campo de trânsito (2007) - olhando para uma "história dos 'calados', [onde se nomeiam] as margens, os silêncios, as fragilidades de todos aqueles que testemunharam os ciclos, as transições, as mudanças desta nação em construção que é Moçambique" (Khan, 2008, p. 134).

Depois de uma conversa com o escritor e historiador, Sheila Khan refere que a memória social e coletiva se entrelaça a um processo de "estruturação de uma identidade nacional", embora tenha outra dimensão, que se prende com "a legitimação do seu poder, sendo detentora da narrativa, de uma espécie de meta-narrativa da História", que mais não é, afinal, do que "a luta pela libertação, [que] legitima o seu poder, e isso passa por um arrancar de todo o passado (...) de demonizar todo um passado colonial"1. Por isso, nas diegeses do autor, este assume-se "como um elo de contrastes, de sinais que projectam, (...), precisamente no que diz respeito à denúncia de uma tentativa política de estabelecer uma ruptura (...) entre os tempos colonial e pós-colonial" (Khan, 2008, pp. 134-135). Em que se afigura clara "a intersecção entre a memória social e o apagamento ou esquecimento, estratégico e político, desse outro tempo colonial, que é premente não esquecer, apagar ou sonegar" (Khan, 2008, p. 135). Havendo, por outro lado, na geração que experienciou a Guerra Colonial, um confronto com o seu próprio processo de desterritorialização cultural, identitária e física. Ou, como refere a personagem Sá Caetana (As visitas do Dr. Valdez, 2004), "pertencemos ao mundo velho, não temos o vigor do novo" (Coelho, 2004, p. 204).

O passado colonial está presente no mundo contemporâneo de muitas maneiras diferentes, sendo incorporado na cultura material de várias formas. De um modo talvez menos tangível, mas nem por isso menos atuante, molda a sociedade, percecionando posicionamentos (L'Estoile, 2008). Segundo Roberto Vecchi, o império "explode hoje em multíplices estilhaços subjetivos cuja forma ainda não se constituiu e está sujeita

\footnotetext{
Sheila Khan, entrevista pessoal, 19 de julho, 2007. Entrevista com João Paulo Borges Coelho. Sines, Portugal.
} 
ao risco de reusos parciais ou revisões interessadas" (2018a, p. 18). Está em curso uma transferência de memória entre gerações, "que deixam entrever sobrevivências possíveis, de passados longínquos e fragmentários, pela força de uma imagem flagrada por um olhar que não a reproduz, mas que a recria" (Vecchi, 2018a, p. 18). E será isso o que restará, depois de já não haver testemunhas vivas dos acontecimentos.

As ideologias e a memória social sobre o passado colonial entre os países de língua portuguesa, sem estarem sujeitas à reflexão e desconstrução crítica, podem contribuir para expressões luso-cêntricas e estereótipos sociais e levar a conflitos intergrupais, discriminação social e exclusão de algumas pessoas (Abadia, Cabecinhas, Macedo, \& Cunha, 2016; Cabecinhas, 2007; Cabecinhas \& Feijó, 2010; Feijó \& Cabecinhas, 2009; M. L. Martins, 2015; Sousa, 2015, 2017). De facto, as memórias coletivas sobre o passado colonial geram tensão entre os denominados "povos de língua portuguesa", cujo contacto com as versões hegemónicas do passado colonial foi propiciado por narrativas culturais, educacionais e históricas que têm sido recorrentemente mobilizadas para fortalecer a identidade nacional e justificar políticas.

A memória cultural (Assmann, 2008) - ou o vínculo entre o passado, o presente e o futuro - constitui um processo contínuo de recordação e esquecimento, em que persiste a reconfiguração dos indivíduos ou do próprio grupo com o passado, sendo que o seu posicionamento é feito relativamente aos lugares de memória emergentes e estabelecidos. Daí que a dinâmica da memória cultural tenha que ser contextualizada, observando-se os fatores sociais em que navega e a forma de como o poder foi exercido.

\section{Presentismo, TeOria Pós-Colonial E inTerCulturalidade}

A memória transformou-se do ponto de vista cultural e político num terreno fértil onde se trava um combate duro pela construção de uma narrativa hegemónica, com cada uma das fações intervenientes a reivindicar a sua própria verdade ou, pelo menos, a sua autoridade de memória. Ainda se olha para a história como se ela fosse construída entre bons e maus e ela é muito mais complexa do que isso. Para Diogo Ramada Curto (2018), trata-se de um desvio de uma questão que é urgente colocar e que se prende com a situação da pesquisa histórica. Advoga que o passado deveria ser estudado através do cruzamento da história com as ciências sociais em geral, assente em fontes e através do desenvolvimento de uma prática analítica que impeça uma prática moralista: "que nos permita pensar as diferenças sociais, a uma escala que ultrapassa a nação, para comprometer migrações e movimentos populacionais" (Curto, 2018, s.p.) e que possibilite, também, "compreender melhor quais as grandes estruturas que, com a força da inércia, se continuam a impor no presente, dificultando a modernização de sociedades como a portuguesa", impedindo o presentismo (Curto, 2018, s.p.). É exatamente nesse sentido que vai a investigação mais recente do historiador António Manuel Hespanha (2019), em Filhos da terra: identidades mestiças nos confins da expansão portuguesa, a história da expansão portuguesa é contada não do ponto de vista da metrópole, mas sim do ponto de vista daqueles que partiram e se instalaram nas margens do império português. 
Hespanha refere que a publicação procura reunir e tratar conjuntamente "elementos para a análise daquilo a que se vem chamando desde há uns anos o 'império sombra' dos portugueses, ou seja, aquele conjunto de comunidades (...), sobretudo na África e na Ásia, [que] se consideravam como 'portugueses'” (Hespanha, 2019, p. 12). Questiona, por isso, a existência de uma "identidade 'portuguesa", asseverando que os problemas começam logo a partir daí, com a definição do objeto de estudo. É que, à medida que as comunidades "portuguesas" vão sendo consideradas, na sua ambiguidade e complexidade dos elementos constitutivos, "a sua identidade vai-se perdendo". E explica: "são tão diferentes entre si que agrupá-las é, antes de tudo, o resultado de termos decidido olhar para elas conjuntamente. E (...) concluímos que isso tem a ver (...) com a forma como, antecipadamente, as imaginámos [como] 'portuguesas'" (Hespanha, 2019, pp. 12-13). Socorrendo-se de Sanjay Subrahmanyam (1995), evidencia mesmo dúvidas sobre a aplicabilidade da expressão "diáspora portuguesa" ${ }^{2}$. Moisés de Lemos Martins (2018) considera que a expansão marítima europeia dos séculos XV e XVI foi um processo que se abriu à alteridade, à diversidade e ao conhecimento do outro, mas que fracassou ao assimilar e destruir toda a diferença, produzindo o colonialismo. O que foi, de resto, sublinhado durante o período do Estado Novo, em que a inoculação da ideologia junto dos territórios colonizados foi feita desde a escola, sublinhando os "valores" em que assentava o regime. O que levou Sephen R. Stoer e Luiza Cortesão a destacarem a "pesada herança da 'portugalidade', como sendo uma 'interculturalidade invertida"', justificando com a tentativa daquele regime procurar atribuir uma "homogeneidade construída", através dos currículos, dos professores, dos materiais escolares, em que o processo educativo se assumia como "uma das vias a que se recorreu, numa tentativa de despertar/desenvolver o sentido de pertença a essa dispersão/diversidade" (Stoer \& Cortesão, 1999, p. 59). O que contrariava a retórica vigente no Estado Novo, a coberto do desenvolvimento de uma política de assimilacionismo, muito embora controlado, terminando, nos anos 6o, já num assimilacionismo pleno, em que extinguiu mesmo a lei do indigenato, conferindo aos naturais a cidadania portuguesa (Torgal, 2009).

Rosa Cabecinhas e Luís Cunha (2008) tipificam, por isso, a interculturalidade enquanto pluralidade distante da diversidade exótica propalada pela propaganda do Estado Novo. A interculturalidade deve ser encarada enquanto processo, que significa que nele participam várias pessoas com desigualdades várias, e que se torna importante perceber "que os lugares que habitamos e as fronteiras que nos separam constituem realidades que em boa medida são irremovíveis, transcendendo assim qualquer retórica multicultural" (Cabecinhas \& Cunha, 2008, p. 7). Importa perceber que o mundo mais pequeno que a globalização fornece não é diretamente proporcional a "formas diferentes de enunciar desigualdades" (Cabecinhas \& Cunha, 2008, p. 7). Os autores alertam, no entanto, para o risco de se poder "confundir diálogo com simetria e interculturalidade com igualdade das partes", que decorre de uma tentativa de simplificar processos,

\footnotetext{
${ }^{2}$ Suart Hall já havia sublinhado "a perspetiva diaspórica da cultura pode ser vista como uma subversão dos modelos culturais tradicionais orientados para a nação" (Sousa, 2013, p. 36), tanto mais que, m tempo de globalização, o conceito de diáspora pode não passar de um contrassenso quando evocado em nome da "portugalidade" (Sousa, 2013).
} 
embora essa atitude seja "mais própria de um imaginário imperial reciclado em tons pós-modernos, que de uma visão desafiadora e que pretenda, de facto, criar renovados sentidos e modos de vida mais justos" (Cabecinhas \& Cunha, 2008, p. 8). O tão em voga diálogo com o "outro", quase que se resume a uma dimensão folclórica, mesmo que a abertura ao "outro" signifique "transformação recíproca", já que, em todo este processo, a expectativa é que exista uma assimetria assente na ideia de que "o outro deve pensar como nós, porque nós pensamos melhor" (Cabecinhas \& Cunha, 2008, p. 9).

João Maria André (2005) propõe alguns princípios tendentes à promoção do diálogo intercultural, que passam pelo conhecimento do "outro" como fator determinante para o desenvolvimento de uma ação prática, assente numa consciência crítica que é necessária à transformação social. Esta lógica intercultural passa pela contestação de uma enunciação universal dos direitos humanos, por uma outra conceção de universalidade, assente no pluralismo e que não seja imposta, para além da recuperação dos traços fundamentais de cada cultura, valorizando o seu recorte simbólico.

É por isso que a definição constante da entrada "interculturalidade" no Dicionário da expansão portuguesa (1415-160o) levanta muitas dúvidas ao estar associada, exatamente à expansão portuguesa, embora traduzida como um conceito surgido nos anos 70 do século $X X$, em França, no seio das ciências da educação, num período de aumento de imigração (Lacerda, 2016, p. 588). A utilização deste conceito no estudo de épocas anteriores justifica-se pela necessidade de identificar no passado fenómenos semelhantes aos pretendidos com um ensino intercultural. Para tal, analisam-se processos que implicaram trocas culturais e amalgamento e não apenas conhecimento ou convívio com uma cultura diferente: "a interculturalidade está relacionada com outros conceitos como aculturação e sincretismo, mas distingue-se claramente da multiculturalidade, que pressupõe apenas o convívio de duas culturas estratificadas e hierarquizadas" (Lacerda, 2016, p. 589). Ora, segundo o referido dicionário, a cultura da expansão portuguesa - como acontece com todas as culturas -, "foi fruto de um processo de osmose, que se desenvolveu pelo choque, pela aceitação e pela rejeição de aspetos de culturas comunicantes" (Lacerda, 2016, p. 589). Os agentes da expansão portuguesa não tinham noção deste processo, mas comportaram-se quase sempre "como portadores de uma cultura acaba$\mathrm{da}$, considerando mesmo que algumas das suas matrizes, nomeadamente o cristianismo, eram formas superiores que deviam ser propagadas" (Lacerda, 2016, p. 589). Desta crença e dos comportamentos daí resultantes nasceram, segundo Teresa Lacerda, "processos de aculturação que geraram fenómenos interculturais" (Lacerda, 2016, p. 589).

Trata-se de uma visão luso tropicalista da história da expansão portuguesa, sendo que é, no mínimo, muito questionável, associar-lhe um recorte de interculturalidade, quando o poder era, então, unilateral, com o sentido único a estar do lado do país colonizador, sendo que quem não obedecia às regras impostas, sofria as respetivas consequências.

É nesse sentido que deixar de considerar as diferenças entre histórias coloniais e processos de colonização pode levar a impor sobre um povo a narrativa pós-colonial de um outro tornando assim esse povo ainda mais invisível, como assinala Ana Paula Ferreira (2007). O que significa que o colonialismo "pode estar a falar em nome de um 
pós-colonialismo crítico, descentrado e não-hegemónico" (Ferreira, 2007, pp. 22-23). O que, segundo Pedro Shacht Pereira, "consubstancia a apropriação de uma metalinguagem crítica, historicamente descontextualizada, mesmo quando feita com a melhor das intenções", e que acarreta "riscos teóricos consideráveis, nomeadamente o de voluntariamente perpetuar a um outro nível a relação colonial que se pretende abolir" (Pereira, 2017, s.p.).

Como refere José Neves (2016), o conhecimento histórico depende tanto de elementos empíricos de um dado passado como da utilização de novas ferramentas teórico-conceptuais que se apurem no presente, sendo que, em história, nenhum assunto pode ser dado por encerrado. Já Paul Ricœur (2000) confirmara a inseparabilidade entre memória e esquecimento, sendo que, como assinala Sanjay Subrahmanyam (Meireles, 2016), a principal função do historiador não é lembrar, já que o trabalho se desenvolve em sentido contrário à dinâmica de acreditar na memória, indo mesmo contra ela, uma vez que esta se revela falsa. No entender de Tzvetan Todorov (2002), a memória, é uma espécie de consciência seletiva do tempo, não se opondo ao esquecimento. A memória é uma interação entre a supressão e a conservação, sendo que restituição integral do passado é impossível uma vez que memória implica sempre uma seleção. O historiador Fernando Bouza cita mesmo um ditado africano que sintetiza o que foi referido sobre o modus operandi da memória: "a memória vai ao bosque e trás de lá a lenha que quer" (Canelas, 2014).

\section{As estátuas de Mouzinho de Albuquerque, do Monumento aos Mortos da I Guerra Mundial e de Salazar Recicladas}

Uma estátua é um objeto imóvel (uma escultura em três dimensões), que pode representar uma entidade real ou imaginária. Os governos coloniais erigiram estátuas nos territórios que colonizaram e que muito materializavam o seu imaginário, numa lógica de centro a partir da metrópole colonizadora, evidenciando a relação simbólica entre Portugal e o seu império. Margarida Calafate Ribeiro (2004) parte do conceito "imaginação do centro", de Boaventura de Sousa Santos, rebatizando-o de "império como imaginação do centro". Sustenta que a elaboração de uma imagem de Portugal enquanto centro realizou-se através do império, encobrindo uma "imagem portuguesa ligada à sua realidade vivencial de periferia que "imagina o centro"' (Ribeiro, 2004, p. 12). Esse ideário remonta ao período da expansão portuguesa, sendo que o colonialismo não constituiu um movimento de sentido único, já que "afetou" tanto os países colonizados, como os países colonizadores. Talvez se perceba, assim, a ideia de Thomas Richards (1993), que se refere ao império como se tratasse de uma nação em excesso, que foi deslocada para longe (talvez demasiadamente longe) conquistando territórios, sem que o respetivo controlo se afigurasse uma tarefa fácil. Como observa Leonor Pires Martins a propósito do império colonial português (Um império de papel, 2012), a ideia de nação deslocou-se para um "imenso aglomerado de territórios, dispersos e distantes entre si, cujo domínio direto e efetivo acabaria por ser mais fictício do que real, mais da ordem do ilusório do que do factual" (L. P. Martins, 2012, p. 20). 
Foram, de resto, as marcas do império, especialmente nesta relação com as "comunidades imaginadas" (Anderson, 1993), que tentaram fixar a ligação, deixando essa ideia bastante clara através do que era retratado.

Os vários domínios ultramarinos só foram apreendidos pelos portugueses através da promulgação de legislação específica (de que é exemplo a publicação, em 1930, do Ato Colonial, que viria a ser extinto em 1951), da propaganda do regime, bem como da difusão de imagens mostrando o "Portugal do Minho a Timor" em toda a sua extensão geográfica. Deste modo, como nota Manuela Ribeiro Sanches a partir de Gary Wilder, foi-se consagrando o estado-nação imperial como um todo coerente, não obstante "as visões distintas, as idiossincrasias, as contradições e os limites das 'missões civilizadoras', baseadas em querelas nacionais", também elas fundadoras do moderno estado-nação (Sanches, 2012, p. 195).

Durante as décadas de 1930 e 1940, Lourenço Marques (atual Maputo), é alvo de várias intervenções estéticas no seu espaço público, tendentes a “'monumentalizar' e 'portugalizar' a cidade, respondendo ao seu estatuto recém-adquirido de capital da Colónia" (Verheij, 2012, p. 11). Destas ações do país colonizador, destacam-se dois monumentos: o Monumento aos Mortos da Primeira Guerra Mundial (do escultor Ruy Roque Gameiro em colaboração com o arquiteto Veloso Reis, de 1935), e o Monumento a Mouzinho de Albuquerque (Simões de Almeida, 1940) (Verheij, 2012, 2013, 2014). À volta destes monumentos têm lugar práticas comemorativas, destinadas a conferir aos monumentos "o estatuto de alegoria da nação portuguesa", desempenhando, assim, um sublinhado papel político na reformulação autoritária do espaço público da cidade "como espaço 'imperial' e na putativa hegemonização das representações da comunidade imaginada como 'Nação'", permitindo assim abordar o uso e a utilidade político-ideológica do monumento do ponto de vista da organização do espaço público (Verheij, 2012, p. 11).

Em Maputo, logo que eclodiu, em Portugal, da Revolução do 25 de Abril, as estátuas coloniais começaram a ser derrubadas (à exceção do Monumento aos Mortos da Primeira Guerra Mundial) e, muitas delas, foram irremediavelmente danificadas. Numa fase posterior, o Governo moçambicano decidiu mudar a dinâmica adotada inicialmente, mostrando a anterior estatuária colonial, preservando a memória ${ }^{3}$, mesmo que a tendência vá no sentido do derrube de vestígios de anteriores opressores, como agora acontece noutros locais do mundo4. É o caso da estátua equestre que homenageava Mouzinho de Albuquerque e estava colocada bem no centro de Maputo, na Praça que no tempo colonial tinha o nome do militar português, que foi Comissário Régio de Moçambique entre 1896 e 1898. Foi trasladada para o Fortaleza de Maputo, onde pode ser

\footnotetext{
3 Na sequência de duas missões de investigação que realizei, em novembro de 2018 , em Maputo, no quadro do CECS-Centro de Estudos de Comunicação e Sociedade e do projeto "Memories, cultures and identities: how the past weights on the present-day intercultural relations in Mozambique and Portugal?", financiado pela Rede Aga Khan para o Desenvolvimento e pela Fundação para a Ciência e Tecnologia, escrevi um artigo para o portal pós-colonial Buala, intitulado "O que vale uma estátua? Memória e descolonização mental em Moçambique". Disponível em http://www.buala.org/pt/ cidade/o-que-vale-uma-esta-tua-memo-ria-e-descolonizac-a-o-mental-em-moc-ambique

${ }_{4}$ É disso exemplo o derrube das estátuas em Charlottesville, na Virgínia, em 2017, destinadas a homenagear símbolos dos Estados Confederados, evidenciando a clivagem entre os seus defensores, evocando a Guerra Civil Americana, e os seus contestatários, que veem nelas símbolos racistas que celebram a escravidão.
} 
vista, e que os recém-casados utilizam como fundo para as fotografias da sua festa de casamento, não obstante personificar o ex-colonizador (Figura 1).

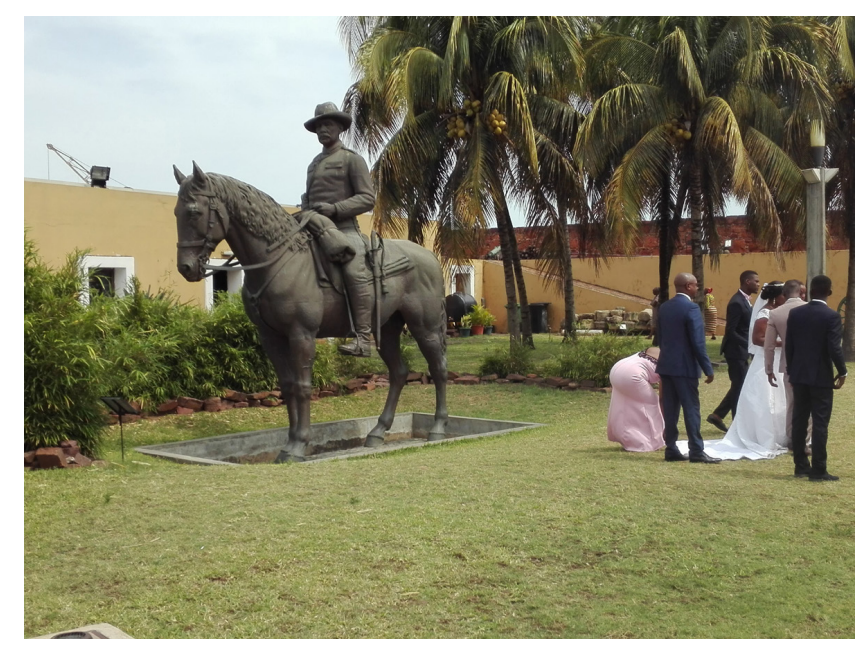

Figura 1: Estátua de Mouzinho de Albuquerque, no Fortaleza de Maputo, onde serve de cenário a fotografias de casamentos (novembro de 2018)

A estátua de Mouzinho de Albuquerque está contextualizada por uma pequena nota. Montado num cavalo, numa escala para além da realidade $(4,90$ metros de altura), Mouzinho não passa indiferente logo que se entra no espaço, que constitui um dos principais monumentos históricos da cidade. Foi para lá trasladado, depois de ter estado durante o período colonial no mesmo local onde, agora, toca o céu uma estátua de bronze de Samora Machel (tem nove metros e meio). A praça continua hoje na sua dinâmica monumental de outrora, sendo ainda pontuada pela Catedral, pelo edifício do Município e pelo Jardim dos Casamentos, conhecido oficialmente por Jardim Botânico Tunduro, que já sofreu várias evoluções desde que foi inaugurado, em 1855.

A estátua de Mouzinho de Albuquerque, que representa o homem que levou Ngungunhane como troféu para Portugal e que está, de resto, sepultado na Fortaleza de Maputo, depois de os seus restos mortais terem sido transladados da Ilha Terceira (Açores), em 1985 -, foi deslocalizada e foi colocada no interior do recinto, ao fundo, em frente à única entrada, e que pontua todo o espaço. O monumento foi retirado do local onde inicialmente foi edificado no primeiro semestre de 1975, na sequência da independência de Moçambique.

A Fortaleza de Maputo está, assim, descolonizada, seguindo as determinações superiores. De resto, os monumentos públicos de Maputo são tutelados pela Universidade Eduardo Mondlane (o mesmo acontece com o Museu de História Natural e com - Museu Nacional de Arte), podendo vislumbrar-se no local vários vestígios da luta contra o colonizador português. Algo parecido com o que acontece em Lisboa em relação ao edifício do Padrão dos Descobrimentos, que foi construído para a Exposição do Mundo Português de 1940, ao serviço da propaganda do Estado Novo e, hoje, acolhe, por exemplo, exposições sobre racismo e escravatura. Não obstante, como refere Celso Azarias Inguane, “a construção da memória social [ser] (...) dominada principalmente 
por tentativas estatais de reproduzir a memória nacional, estabelecendo uma narrativa histórica nacional e em continuidade com as práticas coloniais" (2007, p. ii).

Os cenários para fotografias de casamentos alargam-se, também, à estação de caminhos-de-ferro de Maputo, que fica localizada na Praça dos Trabalhadores, através da utilização das locomotivas, que foram recuperadas e integradas na musealização operada no espaço, que foi inaugurado em junho de 2015. A estação de caminhos-de-ferro ergue-se num edifício de 1910 e é considerada como uma das mais belas do mundo.

No centro da mesma praça, fica localizado o Monumento aos Mortos da Primeira Guerra Mundial (Figura 2).

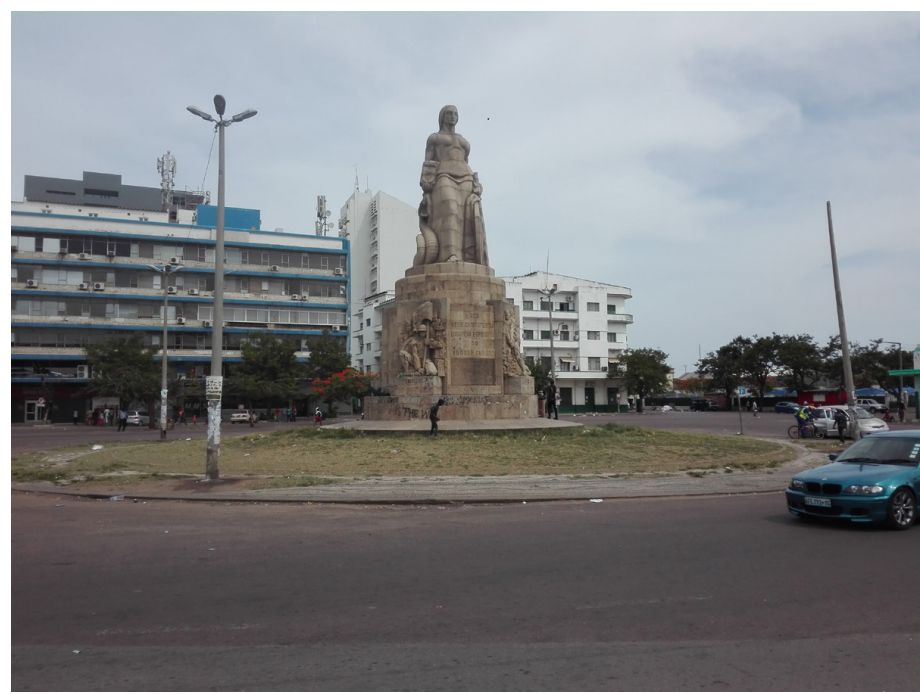

Figura 2: Monumento aos Mortos da Primeira Guerra Mundial, o único monumento erguido em Moçambique no período colonial que retrata os moçambicanos favoravelmente, sendo conhecida localmente por "Senhora da Cobra" (novembro de 2018)

Trata-se de um monumento de pedra, da autoria do escultor Ruy Roque Gameiro em colaboração com o arquiteto Veloso Reis, que homenageia os combatentes africanos e europeus mortos no conflito - e que é o único monumento erguido em Moçambique no período colonial que retrata os moçambicanos de forma favorável (1935) -, e representa uma mulher com uma cobra aos seus pés, tendo na base referências a batalhas que tiveram lugar em Moçambique (Mecula, Quivambo, Nevala e Quionga), em que os guerreiros têm armas nas mãos e os símbolos da bandeira portuguesa. De resto, a estátua propriamente dita, tem na sua mão direita um fragmento de um padrão com as armas nacionais, simbolizando os padrões dos descobrimentos, muito embora na sua memória descritiva se sublinhe um significado mais preciso, já que remete para a reconquista de Quionga, "que assim se insere nitidamente numa história secular de 'descobertas e conquistas"” e é, de forma simultânea, "um palimpsesto, comentário sobre o que pretendia ser: a resposta moderna aos antigos padrões, marcos duráveis de posse e de domínio" (Verheij, 2012, p. 21).

O certo é que, não obstante o recorte colonial da estátua, ela terá sido reciclada pelos cidadãos de Maputo, que a preservaram não pela sua circunstância inicial, que fixou 
o primeiro grande monumento da divulgação da ideia imperial na colónia, "de uma "política do espírito', que visava 'nacionalizar' o espaço colonial” (Verheij, 2012, p. 25), mas devido a uma lenda local, conhecida por "Senhora da Cobra", que nada tem que ver com as razões pelas quais ela foi edificada, bastando compulsar a sua memória descritiva. Segundo essa lenda, havia na região uma cobra em cima de uma árvore que atacava quem por ali passasse. No caminho entre a casa e o rio, mulheres e crianças eram atacadas e mortas pela cobra. Até que uma mulher decidiu pôr fim à situação, cozinhando uma papa e colocando-a num caldeirão à cabeça. Com a papa ainda quente, pôs-se a andar em direção à árvore onde se escondia a cobra. Esta, ao atacar a mulher, entrou no caldeirão da papa, morrendo. A mulher regressou à sua comunidade certa da sua vitória e todos celebraram a sua coragem. A estátua, cuja envolvente está em péssimo estado de conservação faz, por isso, parte do imaginário dos moçambicanos, que valorizam mais a homenagem à mulher salvadora do que os que morreram na Primeira Guerra Mundial, onde se incluem moçambicanos.

Finalmente, uma estátua representando Salazar, que no tempo colonial estava edificada bem no centro de Maputo, ocupando um lugar de destaque, foi colocada na Biblioteca Nacional de Moçambique (que antes era a antiga Biblioteca Municipal, em frente ao Hotel Tivoli, na baixa de Maputo), voltada para a parede (Figura 3).

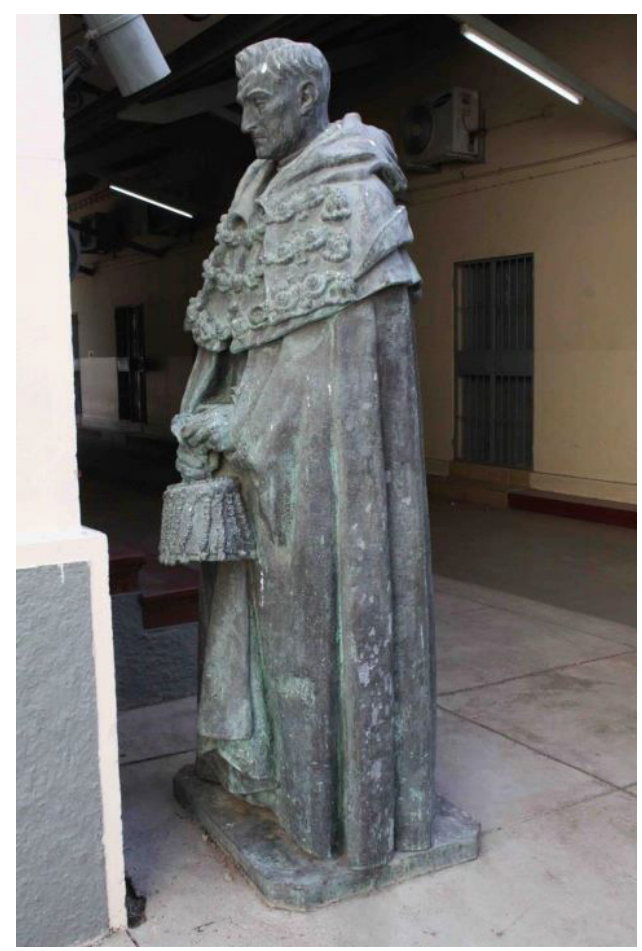

Figura 3: Estátua de Salazar que, no período colonial no centro de Maputo, tendo sido deslocalizada para o edifício da Biblioteca Nacional de Moçambique, voltada para a parede, como se o ex-ditador estivesse de castigo

Fonte: Paulo Pires Teixeira ${ }^{5}$

\footnotetext{
${ }_{5}^{5}$ Retirado d https://delagoabayworld.wordpress.com/category/historia/a-estatua-de-salazar-em-maputo/
} 
É como se os moçambicanos pusessem o ex-ditador português de castigo, numa atitude que configura um humor refinado e que tem sido divulgada nos média e nas redes sociais. Ao contrário da estátua de Mouzinho de Albuquerque, não foi trasladada para a Fortaleza de Maputo, local que, como vimos, foi destinado a mostrar a memória de Moçambique do tempo colonial. A escultura de Salazar, feita de bronze, é de grandes dimensões, e tem autoria de Leopoldo de Almeida, e mostra o ex-ditador de toga e de olhar frontal mas enfrenta, há vários anos, a parede do edifício da Biblioteca Nacional. A este propósito, Joaquim Chissano, ex-chefe de Estado de Moçambique, explica que isso não aconteceu por acaso, já que se pretende mesmo salientar que a história não deve ser esquecida ${ }^{6}$.

\section{NotAS FINAIS}

Roberto Vecchi afirma compreender a hesitação de Walter Benjamin sobre a citação do passado, lembrando que nas teses do autor sobre o conceito de história, socorrendo-se de Robespierre, observara que "a antiga Roma era um passado carregado de agora" (Vecchi, 2018b, s.p.). Nota que o interesse do historiador materialista se reserva ao passado, "pela sua qualidade de ter completamente passado, acabado, de ser definitivamente morto", o que lhe confere a possibilidade de ser citado. E é, segundo Vecchi, nesta hesitação que reside o problema, que tem que ver com os reusos do passado e com a sua citação, "caso o passado esteja definitivamente acabado, apresentará menos riscos, em relação a um passado ainda em discussão", em que as ideologias e os reusos, "poder(ão) alterar profundamente, ou até inverter, os modos da sua evocação" (Vecchi, 2018b, s.p.).

Para a ideologia estado-novista as representações não podiam ser ambíguas, pelo que a escolha, no que à estatuária diz respeito, foi sempre desenvolvida numa dinâmica unidimensional, que "precisava de formas de fixar a relação destes monumentos com a memória coletiva e o presente que proclamava", como assinala Gerbert Verheij. Dessa forma, num tempo pós-colonial, "reintroduzir a conflitualidade que parece ser inerente a qualquer interpretação de imagens na era moderna (...) parece, enfim, necessário para compreender o papel social que o monumento desempenhava em Lourenço Marques" (Verheij, 2012, p. 53). Tanto mais que ajuda a perceber o destino do legado colonial em que, por via da independência de Moçambique (1975), a maioria dos vestígios foi apagada, não obstante a tendência atual, ir no sentido de preservar o que restou na sequência dessa atitude.

Nos casos referenciados por este artigo, relativos à nova vida de duas estátuas coloniais em Maputo, em tempo pós-colonial, e à permanência daquele que foi o primeiro vestígio monumental do Estado Novo na capital moçambicana, muito embora com uma génese deslocada do seu objetivo inicial por parte dos seus habitantes, pode observar-se a importância que tem a preservação da memória, mesmo associada ao antigo

\footnotetext{
${ }^{6}$ Segundo Joaquim Chissano, "existiu Salazar, sim senhor. Ele até fez algumas coisas boas é preciso lembrar - mas ele estando de cara para a frente ou virada para parede para nós é igual porque nós lembramo-nos de tudo o que ele fez de mal, sobretudo ao nosso país, mas também em relação ao povo português". Retirado de https://tvi24.iol.pt/internacional/ estatua/salazar-virado-para-a-parede-de-castigo-em-maputo
} 
colonizador, na vida de um país, ou de uma nação. Nos casos da estátua de Mouzinho de Albuquerque - deslocalizada para o Fortaleza de Maputo -, e da de Salazar - que foi colocada na Biblioteca Nacional voltada para uma parede -, pode afirmar-se que contribuem para o desenvolvimento de uma interculturalidade, numa relação entre o ex-país colonizado, Moçambique, e o país colonizador, Portugal. Esta espécie de "arejamento" simbólico permite questionar por parte dos cidadãos de Maputo (e dos moçambicanos em geral) o seu passado colonial, assumindo essa parte da sua história, tendente a configurar uma identidade, menos povoada de espaços em branco, que navegam num mar de memória e de esquecimento, e que pontuam o processo de construção da nação moçambicana (Khan et al., 2016).

Em ambos os casos, trata-se de uma espécie de descolonização mental (Mbembe, 2017; Thiong'o, 1986), que passa pela problematização da forma como o passado colonial pesa nas relações interculturais dos dias de hoje em Moçambique, quando o país olha para o seu passado, subjugado pela colonização portuguesa. Nesse sentido, promove-se a interculturalidade, de forma a permitir ultrapassar equívocos e dirimir ressentimentos. Marc Ferro (2009) refere-se à existência de uma reciprocidade dos ressentimentos, observando que o ressentimento não é apanágio, apenas, daqueles que no início eram identificados como vítimas. A investigação descobre que, simultânea ou alternadamente, o ressentimento pode afetar, inibir não apenas uma das partes em causa, mas as duas. O caso da reação que se segue a uma revolução é óbvio, mas os percursos deste tipo são múltiplos e variados.

Como defende Maria Paula Meneses, urge abrir as narrativas históricas, "apostando em histórias interligadas, local e regionalmente, desafiando as heranças das representações coloniais". Dessa forma, a descolonização deve assumir-se "como um ato de controlo da consciência, um ato de libertação da opressão do conhecimento enquanto monocultura". É nesse contexto que a entrada no século XXI requer "uma cartografia em rede, dialógica, mais complexa e cuidada da diversidade, que torne visíveis alternativas epistémicas e ontológicas, para além das fraturas abissais" (Meneses, 2018, p. 133).

O tempo pós-colonial não cancela o tempo colonial, embora o recicle num jogo estético cheio de indiferença e de aspetos lúdicos: a estátua colonial representa uma ausência/indiferença, mesmo que preencha ludicamente um espaço fotografável. Não obstante, o recorte estatal moçambicano em reproduzir a memória nacional, numa narrativa em linha com as práticas coloniais. Mesmo que Moçambique seja, em si mesmo, uma memória da colonização.

O que vale, então, uma estátua?, pode perguntar-se. Não basta que a política moçambicana aposte na memória, exibindo artefactos. Ela terá que ser acompanhada por uma componente educativa, para que se interpretem os símbolos e se perceba a porção visível da história do país evidenciada, nomeadamente através da estatuária. Caso contrário, tirar fotos com Mouzinho de Albuquerque em fundo, mesmo que este esteja contextualizado, não terá que ver com nenhuma descolonização mental, mas com outra coisa, não obstante a liberdade que cada um tem. O mesmo se poderá passar em relação à estátua de Salazar voltada para a parede da Biblioteca Nacional que, se não tiver contexto, poderá ser interpretada como mero ressentimento. 


\section{FinANCIAMENTO}

Investigação desenvolvida no contexto do projeto "Memories, cultures and identities: how the past weights on the present-day intercultural relations in Mozambique and Portugal?", financiado pela Rede Aga Khan para o Desenvolvimento e pela Fundação para a Ciência e Tecnologia. Tradução do artigo para Inglês financiada pelo mesmo projeto.

\section{REFERÊNCIAS}

Abadia, L., Cabecinhas, R., Macedo, I. \& Cunha, L. (2016). Interwoven migration narratives: identity and social representations in the Lusophone world. Identities - Global Studies in Culture and Power, 25(3), 339-357. https://doi.org/10.1080/1070289X.2016.1244062

Anderson, B. (1993). Imagined communities: reflections on the origin and spread of nationalism. Londres: Verso.

André, J. M. (2005). Diálogo intercultural, utopia e mestiçagens em tempos de globalização. Coimbra: Ariadne Editora.

Assmann, J. (2008). Communicative and cultural memory. In A. Erll \& A. Nunning (Eds.), Media and cultural memory (pp. 109-118). Berlim/Nova Iorque: Walter de Gruyter.

Cabecinhas, R. (2007). Preto e branco: a naturalização da discriminação racial. Porto: Campo das Letras.

Cabecinhas, R. \& Cunha, L. (2008). Introdução. Da importância do diálogo ao desafio da interculturalidade. In R. Cabecinhas \& L. Cunha (Eds.), Comunicação intercultural. Perspectivas, dilemas e desafios (pp. 7-12). Porto: Campo das Letras.

Cabecinhas, R. \& Feijó, J. (2010). Colective memories of Portuguese colonial action in Africa: representations of the colonial past among Mozambicans and Portuguese youths. International Journal of Conflict and Violence, 4.1, 38-44. Retirado de http://hdl.handle.net/1822/11738

Canelas, L. (2014, 14 de dezembro). Entrevista a Fernando Bouza: "O Portugal dos Filipes é uma criação portuguesa". Público. Retirado de https://pt.scribd.com/ document/252415558/O-Portugal-Dos-Filipes-e-Uma-Criacao-Portuguesa-PUBLICO

Coelho, J. P. B. (2004). As visitas do Dr. Valdez. Lisboa: Caminho.

Curto, D. R. (2018, 7 de maio). Atraso da História. Expresso. Retirado de http://expresso.sapo.pt/ blogues/2018-05-07-Atraso-da-historia\#gs.xt=EdoU

Feijó, J. \& Cabecinhas. R. (2009). Representações da história de Moçambique por parte de estudantes universitários de Maputo. In Anuário Internacional de Comunicação Lusófona, 37-52. Vila Nova de Famalicão: Húmus/Lusocom.

Ferreira, A. P. (2007). Specificity without exceptionalism: towards a critical Lusophone postcoloniality. In P. de Medeiros (Ed.), Lusophones literatures and postcolonialism (pp. 21-40). Utrecht: University of Utrecht, Portuguese Studies Center.

Ferro, M. (2009). O ressentimento na história. Lisboa: Teorema.

Halbwachs, M (1950/1990). A memória colectiva. São Paulo: Vértice.

Hespanha, A. M. (2019). Filhos da terra. Identidades mestiças nos confins da expansão portuguesa. Lisboa: Tinta da China. 
Inguane, C. A. (2007). Negotiating social memory in postcolonial Mozambique: the case of heritage sites in Mandhlakazi district. Master of Arts in Social Anthropology. Johannesburg: University of the Witwatersrand.

Khan, S. (2008). Narrativas, rostos e manifestações do pós-colonialismo moçambicano nos romances de João Paulo Borges Coelho. Gragoatá, 13(24), 131-144. Retirado de http://www.gragoata.uff.br/index.php/ gragoata/article/view/252

Khan, S., Falconi, J. \& Krakowska, K. (2016). Moçambique, novas gerações em diálogo. Cerrados, 41, 314-329.

L'Estoile, B. (2008). The past as it leaves now: an anthropology of colonial legacies. Social Anthropology, 16(3), 267-279. https://doi.org/10.1111/j.1469-8676.2008.00050.x

Lacerda, T. (2016). Interculturalidade. In F. C. Domingues (Dir.), Dicionário da expansão portuguesa (14151600), Volume 2 (pp. 588-593). Lisboa: Círculo de Leitores

Marschall, S. (2009). Landscape of memory: commemorative monuments, memorials and public statuary in postapartheid South Africa, vol. 15. Boston: Brill.

Martins, L. P. (2012). Um império de papel. Lisboa: Edições 70.

Martins, M. L. (Ed.) (2015). Lusofonia e interculturalidade - promessa e travessia. Famalicão: Húmus.

Martins, M. L. (2018, 6 de abril). Descobertas/Descobrimentos e expansão. Viagem e travessia. Portugalidade e lusofonia. Correio do Minho. Retirado de https://correiodominho.pt/cronicas/ descobertas-descobrimentos-e-expansao-viagem-e-travessia-portugalidade-e-lusofonia/9812

Mbembe, A. (2017). Crítica da razão Negra. Lisboa: Antígona.

Meireles, L. (2016, 28 de agosto). Entrevista a Sanjay Subrahmanyam "O império português era um império em rede". Expresso, pp. 50-58.

Meneses, M. P. (2018). Colonialismo como violência: a "missão civilizadora" de Portugal em Moçambique. Revista Crítica de Ciências Sociais[Número especial], 115-140.

Neves, J. (2016). Os sujeitos da História. In J. Neves (Ed.), Quem faz a História? Ensaios sobre o Portugal contemporâneo (pp. 9-16). Lisboa: Tinta da China.

Nora, P. (1989). Between memory and history: 'les lieux de mémoire'. Representations, 26, 7-24. https://doi. org/10.2307/2928520

Pereira, P. S. (2017, 25 de agosto). A lusofonia, a ambivalência e as grelhas do ministro. Público. Retirado de https://www.publico.pt/2017/08/25/mundo/ opiniao/a-lusofoniaa-ambivalencia-e-as-grelhas-do-ministro-1782621

Ribeiro, A. S. (2018). Pós-memória e compaixão - a razão das emoções. Jornal Memoirs, p. 15. Retirado de https://www.ces.uc.pt/ficheiros2/files/MEMOIRS-encarte.pdf

Ribeiro, A. S. \& Ribeiro, M. C. (2018). A past that will not go away. The colonial war in Portuguese postmemory. Lusotopie, 17, 2, 277-300. https://doi.org/10.1163/17683084-12341722

Ribeiro, M. C. (2004). Uma história de regressos, império, guerra colonial e pós-colonialismo. Porto: Edições Afrontamento.

Richards, T. (1993). The imperial archive. Knowledge and the fantasy of Empire. Londres/ Nova lorque: Verso.

Ricœur, P. (2000). La Memóire, l'Histoire, l'Oubli. Paris: Éditions du Seuil. 
Sanches, M. R. (2012). A bem da Europa e das suas nações. In L. P. Martins, Um império de papel (pp. 195207). Lisboa: Edições 70.

Shepherd, N. \& Robins, S. (Eds.) (2008). New South African keywords. Johannesburg: Jacana/Athens: Ohio University Press.

Sousa, V. (2013). O conceito de diáspora em tempo de globalização. A relação entre império, lusofonia e 'portugalidade': um contrassenso? In M. Ledo, X. López \& M. Salgueiro (Eds.), Anuário Internacional de Comunicação Lusófona (17-29). Santiago de Compostela: Lusocom/Agacom.

Sousa, V. (2015). Da 'portugalidade' à lusofonia. Tese de Doutoramento, Universidade do Minho, Braga, Portugal. Retirado de http://repositorium.sdum.uminho.pt/handle/1822/38461

Sousa, V. (2017). Da 'portugalidade’ à lusofonia. Vila Nova de Famalicão: Húmus.

Stoer, S. R. \& Cortesão, L. (1999). "Levantando a pedra" - da pedagogia inter/multicultural às políticas educativas numa época de transnacionalização. Porto: Afrontamento.

Subrahmanyam, S. (1995). O império asiático português 1500-1700. Uma história política e económica. Lisboa: Difel.

Thiong'o, N. (1986). Decolonising the mind: the politics of language in African literature. Portsmouth: Heinemann Educational.

Todorov, T. (2002). Memória do mal, tentação do bem. Uma Análise do Século XX. Porto: Edições Asa.

Torgal, L. R. (2009). Estados Novos, Estado Novo, Vol. 1. Coimbra: Imprensa da Universidade de Coimbra.

Vecchi, R. (2018a). Depois das testemunhas: sobrevivências. Jornal Memoirs, p. 18. Retirado de https://www. ces.uc.pt/ficheiros2/files/MEMOIRS-encarte.pdf

Vecchi, R. (2018b, 19 de dezembro). Os (re)usos do passado. [Post em blogue]. Retirado de http://www. buala.org/pt/a-ler/os-reusos-do-passado

Verheij, G. (2012). Monumentalidade e espaço público em Lourenço Marques nas Décadas de 1930 e 1940. On the waterfront, 20, 11-54.

Verheij, G. (2013). Art and politics in the former "Portuguese Colonial Empire". The monument to Mouzinho de Albuquerque in Lourenço Marques. RIHA Journal oo65. Retirado de http://www.riha-journal.org/ articles/2013/2013-jan-mar/verheijmouzinho-monument-marques

Verheij, G. (2014). Monumentos coloniais em tempos pós-coloniais. A estatuária de Lourenço Marques. In B. F. Torras (Ed.), Actas do IV Congresso de História da Arte Portuguesa em homenagem a José Augusto França (pp. 36-45). Lisboa: APHA.

\section{NOTA BIOGRÁFICA}

Vítor de Sousa é doutorado em Ciências da Comunicação (Comunicação Intercultural), pela Universidade do Minho, com a tese Da 'portugalidade' à lusofonia, é mestre (especialização em Educação para os Média) e licenciado (especialização em Informação e Jornalismo) na mesma área. Entre as suas áreas de investigação constam as questões em torno da identidade, Estudos Culturais, Educação para os Média e teorias de Jornalismo. É investigador do CECS, onde integra o Grupo de Estudos Culturais, membro 
do Projeto "CulturesPast\&Present - Memories, cultures and identities: how the past weights on the present-day intercultural relations in Mozambique and Portugal?" (FCT/Aga Khan) e do Museu Virtual da Lusofonia. É sócio da Sopcom, ECREA e da Associação dos Amigos da Biblioteca Municipal de Penafiel. Venceu o Prémio Científico Mário Quartim Graça 2016, que distinguiu a melhor tese concluída nos últimos três anos na área das Ciências Sociais e Humanas, em Portugal e na América Latina. Foi jornalista (1986-1997) e assessor de imprensa (1997-2005).

ORCID: https://orcid.org/oooo-0002-6051-0980

Email: vitordesousa@gmail.com

Morada: CECS-Centro de Estudos de Comunicação e Sociedade, ICS-Instituto de Ciências Sociais, Universidade do Minho, Campus de Gualtar, 4710-057 Braga

* Submetido: 04/02/2019

$*$ Aceite: 07/03/2019 